- Revista de Iniciação à Docência, v. 5, n. 3, 2020 -

Publicação: março, 2021 - ISSN 2525-4332

\title{
A DISCIPLINA DE DIDÁTICA NO CONTEXTO DE UM CURSO STRICTO SENSU DA ÁREA DA MATEMÁTICA NA UNIVERSIDADE ESTADUAL DE LONDRINA
}

Carolaine Criele dos Santos Silva ${ }^{1}$

Cláudia Chueire de Oliveira ${ }^{2}$

RESUMO: O texto refere-se aos resultados obtidos em projeto iniciação científica intitulado " $A$ disciplina de Didática no contexto de curso stricto sensu da área da Matemática na Universidade Estadual de Londrina". O projeto teve como objetivo analisar a contribuição dos conteúdos da Didática, presentes nas disciplinas de Didática e Epistemologia das Ciências e A Avaliação da Aprendizagem Escolar. A metodologia assentou-se nos pressupostos das abordagens qualitativas, por meio da pesquisa bibliográfica e documental. Os dados coletados foram tratados a partir da ordenação, classificação e análise dos descritores ementa e conteúdos. As conclusões indicam que os programas de ensino estudados consideram a dimensão pedagógica da formação de professores de Matemática ao tratarem de elementos essenciais para o trabalho relativo à didática e à avaliação da aprendizagem e colaboram para que a formação dos alunos do stricto sensu avance em direção à pesquisa referente ao ensino da Matemática.

Palavras-Chave: Didática; Formação de Professores; Educação Superior; Ensino de Matemática.

\begin{abstract}
This text refers to the results obtained in a scientific initiation project entitled "The discipline of Didactics in the context of a stricto sensu course in the area of Mathematics at the State University of Londrina". The project aimed to analyze the contribution of the contents of Didactics, present in the disciplines of 'Didactics and Epistemology of Sciences' and 'The Evaluation of School Learning'. The methodology was based on the assumptions of the qualitative approach through bibliographic and documentary research. The data collected were treated based on the ordering, classification and analysis of the descriptors course description and content. The conclusions indicate that the course syllabuses studied consider the pedagogical dimension of the training of mathematics teachers when dealing with essential elements for the work related to didactics and the assessment of learning and collaborate so that the training of students in the stricto sensu advances towards the research related to the teaching of mathematics.
\end{abstract}

Key words: Didactics; Teacher Training; Higher Education; Mathematics Teaching.

\section{Introdução}

Este texto refere-se ao projeto de iniciação científica "A disciplina de Didática no contexto de curso stricto sensu da área da Matemática na Universidade Estadual de Londrina", desenvolvido entre os anos de 2018 e 2019, como parte integrante do projeto de pesquisa 'A disciplina de Didática na Universidade Estadual de Londrina (UEL): o que indicam os planos de ensino no processo de formação de professores'.

O projeto focalizou o estudo de uma dada realidade escolarizada, stricto sensu, como um dos possíveis campos de formação de professores, entendendo que a mediação

\footnotetext{
${ }^{1}$ Estudante do curso de Licenciatura em Pedagogia da Universidade Estadual de Londrina (UEL). E-mail: < carolainesilva19o@gmail.com >.

${ }^{2}$ Doutora em Educação (UNICAMP). Docente do Departamento de Educação da Universidade Estadual de Londrina (UEL). E-mail: < cchueire@uel.br >.
} 
necessária entre os meios didático-pedagógicos e os objetivos sócio-políticos da educação na sociedade são temas de pesquisa da Didática.

Os objetivos deste projeto foram: i) analisar a contribuição dos conteúdos da Didática, presentes nas disciplinas de Didática e Epistemologia das Ciências e A Avaliação da Aprendizagem Escolar relativas ao Programa Stricto Sensu de Ensino de Ciências e Educação Matemática da UEL; e ii) verificar quais foram as bases teórico-metodológicas da formação de professores veiculadas nos referidos programas de ensino entre os anos de 2012 e 2017.

As bases teóricas deste estudo foram norteadas pelos debates contemporâneos relativos ao ensino de Didática que propõem a “[...] apropriação de princípios e práticas que arquitetam caminhos para a constituição pedagógica e sociopolítica da formação do educador [...]" (MANIFESTO, 2014). Libâneo (2002) é que explicita:

Didática é uma disciplina que estuda o processo de ensino no seu conjunto, no qual os objetivos, conteúdos, métodos formas organizativas da aula se relacionam entre si de modo a criar as condições e os modos de garantir aos alunos uma aprendizagem significativa. Ela ajuda o professor na direção e orientação das tarefas do ensino e da aprendizagem fornecendo-lhe segurança profissional (LIBÂNEO, 2002, p. 5).

A didática, quando trata dos objetivos, conteúdos, meios e avaliação do processo de ensino, relaciona tais elementos que são pedagógico-didáticos às finalidades sóciopolíticas. Não há como citar o pedagógico sem ter uma concepção estruturada de homem e de sociedade. Assim, o planejamento do ensino deve responder sobre qual o significado social do ensinar. O plano de ensino, por sua vez, é a expressão que registra tais elementos.

No caso da Matemática há que destacar que as aproximações entre a Didática Geral e as especificidades da própria ciência nos espaços acadêmicos oferecem amparo para o ensino na área, mas também permitem extrair elementos de discussão e reflexão para a generalização referente aos aspectos que compõem historicamente a Didática Geral:

[...] o ensino é um campo de interesse comum a vários campos do conhecimento. Não há como desconhecer a pluridimensionalidade do fenômeno ensino. Mas nós, da Didática, dizemos: é precisamente em razão dessa pluridimensionalidade que se torna necessário postular o enfoque propriamente didático dos fenômenos educativos para, partindo daí, buscar a contribuição de outros campos científicos (LIBÂNEO, 2002, p. 8).

O referido autor acrescenta que compete ao professor que atua com a Didática facilitar a articulação de conhecimentos dos alunos e os conteúdos pedagógicos, de modo que o ensino seja colocado em debate dentro de um contexto sócio-histórico. Como uma possibilidade de campo de integração, a Didática aborda o ensino e o ensino de determinada área do conhecimento. Libâneo (2002) é novamente quem apresenta ideias interessantes a esse respeito:

Tomar a Didática como disciplina de integração ou disciplina-síntese, implica reconhecer que ela tem dois campos conexos e integrados de saber, o ensino e o ensino de determinada matéria, [... ]. Para que um professor transforme as bases da ciência e que é especialista, em matéria de ensino, e com isso oriente o ensino dessa matéria para a formação da personalidade do aluno, é preciso que ele 
- Revista de Iniciação à Docência, v. 5, n. 3, 2020 -

Publicação: março, 2021 - ISSN 2525-4332

tenha: a) formação na matéria que leciona; b) formação pedagógico-didática na qual se ligam os princípios gerais que regem as relações entre o ensino e a aprendizagem com problemas específicos do ensino de determinada matéria ( $\mathrm{p}$. 12).

A importância de examinar com profundidade as questões anunciadas neste projeto de iniciação científica se justificou por avaliarmos que a Didática possibilita aos cursos que formam professores a compreensão do "[...] papel fundante na mediação entre a formação específica e a formação pedagógica [...] na reinvenção do ensino, reelaborando seus processos" (MANIFESTO, 2014), especialmente no que diz respeito às disciplinas que promovem formação docente originada no stricto sensu na área da Matemática da UEL. Os conteúdos da ciência ensinada em didática específica analisam questões próprias do ensino que realiza, enquanto a Didática, por sua vez, "[...] abstrai as particularidades das distintas matérias e generaliza as manifestações e leis específicas do ensino e aprendizagem nas diferentes disciplinas e formas de ensino" (LIBÂNEO, 2002, p. 13).

A metodologia da pesquisa desenvolvida baseou-se nos pressupostos das abordagens qualitativas dentro do que foi explicitado por Minayo (1994), considerando que busca no universo que investiga, os significados que caracterizam espaços mais profundos e relações mais duradouras na construção do conhecimento.

A pesquisa bibliográfica e a pesquisa documental auxiliaram a compor um mapeamento da atual situação da Didática ensinada nas disciplinas de Didática e Epistemologia das Ciências e Avaliação da Aprendizagem Escolar relativas ao Programa de Pós-Graduação Stricto Sensu de Ensino de Ciências e Educação Matemática da UEL, ponderando que os aspectos que registram a intenção de um processo pedagógico podem ser os próprios e possíveis mobilizadores na construção do conhecimento da área. $A$ análise documental complementou informações obtidas por outras técnicas e auxiliou a desvelar aspectos novos de um tema (LÜDKE; ANDRÉ, 1986). Os documentos forneceram evidências para fundamentar afirmações contextualizadas, pois surgiram do determinado contexto.

A metodologia para tratamento dos dados se desenvolveu a partir da "ordenação, classificação" dos mesmos e, posteriormente, "análise propriamente dita" (MINAYO, 1994, p.26) com auxílio dos descritores ementa e conteúdos de ensino. Pretendeu-se contextualizar características gerais das temáticas propostas para o ensino da Didática no período indicado. No curso do artigo não identificaremos os docentes responsáveis pelos programas analisados, visando a preservação desses profissionais.

De acordo com Minayo (1994), "toda investigação se inicia com um problema, com uma questão, por uma dúvida ou com uma pergunta, articuladas a conhecimentos anteriores, mas que também podem demandar a criação de novos referenciais" (p. 18). Portanto, a questão norteadora da investigação foi a seguinte: Como os programas das disciplinas de Didática no contexto de curso stricto sensu, favorecem a formação do professor da área da Matemática? 
- Revista de Iniciação à Docência, v. 5, n. 3, 2020 -

Publicação: março, 2021 - ISSN 2525-4332

Diante do exposto, seguem as próximas etapas que caracterizaram este trabalho de iniciação científica, a partir da realidade que foi alvo do estudo.

\section{A realidade investigada}

A UEL foi fundada em 1970 e reconhecida um ano depois. Incorporou as faculdades pioneiras de Direito, Filosofia e Odontologia, criadas na década de 50. Nos 50 anos de ensino, pesquisa e extensão a UEL vem cumprindo a missão de desenvolver novas tecnologias, criar oportunidades e aprimorar recursos humanos (UNIVERSIDADE ESTADUAL DE LONDRINA, 2019)

A pós-graduação da UEL contava, no decorrer deste estudo, com 32 cursos de Doutorado e 49 Mestrados, atendendo a mais de três mil estudantes de stricto sensu. Por meio de programas institucionais, tem incentivado a iniciação científica em todos os níveis de ensino, a pesquisa em laboratórios multiusuários, orientado processos de revalidação de diplomas estrangeiros e ampliado a sua inserção internacional.

O Programa de Pós-Graduação em Ensino de Ciências e Educação Matemática, foco deste trabalho, foi implantado em 2002, envolvendo os departamentos de Física, Matemática, Biologia, Geociências, Filosofia e Química e propõe-se à formação de professores/pesquisadores nas áreas de Ensino de Ciências e Educação Matemática. (UNIVERSIDADE ESTADUAL DE LONDRINA, 2019a).

O perfil do profissional que se deseja formar é de um professor-pesquisador que por meio de sua produção intelectual e científica e de sua atividade profissional possa contribuir para o desenvolvimento do ensino de ciências e da educação matemática. (UNIVERSIDADE ESTADUAL DE LONDRINA, 2019a). O objetivo geral do Programa é:

Formar pesquisadores/docentes na área de Ensino de Ciências e Educação Matemática para atuarem em todos os níveis de ensino e desenvolverem pesquisas que levem a uma maior compreensão sobre a elaboração/construção dos saberes docentes/discentes no processo de ensino-aprendizagem nas áreas de conhecimento pertinentes ao programa (UNIVERSIDADE ESTADUAL DE LONDRINA, 2019a).

Os objetivos específicos são:

1. Desenvolver reflexões sobre os processos de ensino e aprendizado em Ciências e Matemática, investigando as formas, modelos, estratégias, metodologias e enfoques que possibilitam a apropriação do conhecimento científico e matemático.

2. Contribuir para o ensino e aprendizado de Ciências e Matemática com investigações e reflexões acerca dos fundamentos epistemológicos, sociais e culturais do saber escolar e do conhecimento científico e matemático.

3. Investigar a utilização de materiais didáticos diversos (textos, equipamentos, experimentos, jogos, vídeos e softwares), bem como as chamadas novas tecnologias (microcomputadores, internet) na construção de saberes escolares no ensino/aprendizagem de Ciências e Matemática.

4. Investigar como os diferentes espaços (salas de aula, laboratórios, centros e museus de ciência) influenciam na elaboração dos saberes escolares. 
- Revista de Iniciação à Docência, v. 5, n. 3, 2020 -

Publicação: março, 2021 - ISSN 2525-4332

5. Procurar construir soluções efetivas para questões suscitadas pela prática docente, mediante a investigação de questões reais de sala de aula, em todos os níveis de ensino, e a reflexão integrada e interdisciplinar entre as áreas envolvidas. (UNIVERSIDADE ESTADUAL DE LONDRINA, 2019a).

Visando conhecer um pouco mais sobre a produção acadêmica a respeito do tema, encontramos em Coura e Passos (2017), um estudo que sistematizou pesquisas que tratam da formação de professores em programas stricto sensu do país, entre os anos de 2001 e 2012. Os autores indicam que há no referido período 30 dissertações ou teses relativas a concepções e práticas e formação de professores que atuam em licenciaturas em Matemática. Os resultados do estudo indicam duas situações:

[...] as dissertações e teses que se concentraram nas práticas de formadores de professores de matemática mostraram um movimento desses formadores para transpor a reprodução das vivências que experimentaram em sua formação e avançar no sentido de considerar a complexidade do trabalho do professor que estão formando [e que] a temática formação, aprendizagem, desenvolvimento ou constituição profissional do formador de professores de matemática denota a dupla relação que o formador mantém com a formação de professores: ao ensinar conteúdos matemáticos, ensina um modo de ser professor e, nesse processo, também se forma, pois precisa mobilizar saberes para empreender práticas que atendam às demandas do seu contexto profissional (COURA; PASSOS, 2017, p. 2021).

O Programa de Pós-Graduação em Ensino de Ciências e Educação Matemática mostra em seus objetivos e nos detalhes sobre o perfil do profissional que deseja formar, comum acordo com as recentes propostas apresentadas em âmbito nacional, ou seja, a formação de bons professores para o ensino da Matemática e com responsabilidade social acerca do seu fazer docente. Para isso considera que é necessário encontrar soluções efetivas para as demandas trazidas da prática docente, com investigação de temas concretos das salas de aula em todos os níveis de ensino e por meio da reflexão interdisciplinar com áreas afins. Nesse contexto, é importante que as disciplinas forneçam material essencial com os campos conexos e integrados de saber, o ensino e o ensino de determinada matéria, conforme exposto por Libâneo (2002).

Assim, apresentamos a seguir, a ementa e o conteúdo programático das duas disciplinas analisadas, visando examinar a presença dos elementos citados pelos estudiosos da área de Didática. Convém destacar que as referidas disciplinas foram identificadas na grade curricular do referido curso, disponibilizados no site da UEL. Uma correspondência foi enviada para o Coordenador do Programa solicitando cópia dos programas entre os anos de 2012 e 2017. Foram dois os programas obtidos. O Quadro 1 informa os dados das disciplinas investigadas no presente estudo. 
- Revista de Iniciação à Docência, v. 5, n. 3, 2020 -

Publicação: março, 2021 - ISSN 2525-4332

QUADRO 1 - Dados das disciplinas investigadas no presente estudo.

\begin{tabular}{|c|c|c|c|}
\hline ANO & DISCIPLINA & EMENTA & PROGRAMA 3 \\
\hline 2011 & $\begin{array}{l}\text { A avaliação da } \\
\text { aprendizagem } \\
\text { escolar }\end{array}$ & $\begin{array}{l}\text { A avaliação } \text { da } \\
\text { aprendizagem em sala } \\
\text { de aula. A avaliação } \\
\text { como prática de } \\
\text { investigação. O erro } \\
\text { como fonte de } \\
\text { aprendizagem. Alguns } \\
\text { dos instrumentos de } \\
\text { avaliação da } \\
\text { aprendizagem escolar. }\end{array}$ & $\begin{array}{l}\text { A avaliação da aprendizagem em sala de aula. Causas } \\
\text { e finalidades da avaliação. Métodos, tipos, } \\
\text { estratégias e procedimentos da avaliação escolar. } \\
\text { Concepção de avaliação; erro }- \text { concepção e } \\
\text { classificação. O erro como fonte de aprendizagem. } \\
\text { funções e propósitos da avaliação escolar. Alguns } \\
\text { instrumentos de avaliação da aprendizagem escolar. } \\
\text { Intervenção: procedimentos e estratégias; quem } \\
\text { avalia, o quê, quando, como, porque se avalia. As } \\
\text { notas e/ou outras formas de apreciação quantitativa } \\
\text { ou qualitativa. Regulação da aprendizagem. A } \\
\text { avaliação como prática de investigação. Análise da } \\
\text { produção escrita como estratégia de avaliação. } \\
\text { Semelhanças (especificidades), diferenças e } \\
\text { contradições presentes nos dois autores estudados. } \\
\text { A articulação entre formação e avaliação. }\end{array}$ \\
\hline 2016 & $\begin{array}{l}\text { Didática e } \\
\text { Epistemologia } \\
\text { das Ciências }\end{array}$ & $\begin{array}{lr}\text { Estudos da relação entre } \\
\text { didática, } & \text { didáticas } \\
\text { específicas } & \text { e } \\
\text { epistemologia } & \text { das } \\
\text { ciências } & \text { naturais. } \\
\text { Estudos } & \text { de } \\
\text { epistemologia } & \text { como } \\
\text { teoria do conhecimento } \\
\text { e no âmbito das } \\
\text { disciplinas em ciências } \\
\text { naturais. }\end{array}$ & $\begin{array}{l}\text { Apresentação da disciplina. A trajetória histórica da } \\
\text { didática. A emergência da didática das ciências como } \\
\text { campo específico de conhecimento. Conhecimento e } \\
\text { ação docente: considerações sobre o processo } \\
\text { cognitivo. Conhecimento como rede: metáfora como } \\
\text { paradigma e como processo. Avaliação educacional: } \\
\text { das técnicas aos valores. Contribuiciones de la filosofia } \\
\text { de la ciencia a la didática de las ciencias. Da nova } \\
\text { filosofia da ciência ao ensino de ciências. História, } \\
\text { Epistemologia e Didática das ciências: Relações } \\
\text { necessárias. Mitos da didática das ciências acerca dos } \\
\text { motivos para incluir a natureza da ciência no ensino } \\
\text { das ciências. Alfabetização científica: revisão } \\
\text { histórica. Seminários. Entrega do trabalho final. }\end{array}$ \\
\hline
\end{tabular}

Considerando os tópicos descritos, destacamos que alguns são tradicionalmente focos de estudo da Didática, a saber: avaliação da aprendizagem escolar; trajetória histórica da Didática; conhecimento e ação docente.

No primeiro momento, vamos analisar os conteúdos relativos à avaliação da aprendizagem escolar. Avaliação presume acolhimento e visa transformação. As finalidades e funções da avaliação da aprendizagem são diferentes das provas e exames pois vão além da medida. Luckesi (2006) define a avaliação como um ato amoroso, no sentido de que seja um ato acolhedor, integrativo e inclusivo. $O$ autor aponta que o objetivo da avaliação como diagnóstico é a inclusão pois o selecionar leva a exclusão.

Romão (apud Berbel, 2001) assinala que:

A avaliação da aprendizagem é um tipo de investigação e é, também, um processo de conscientização sobre a 'cultura primeira' do educando, com suas

\footnotetext{
${ }^{3}$ A palavra Programa foi trazida para este estudo conforme estava descrita. No entendimento das autoras, refere-se ao conteúdo programático a ser trabalhado na disciplina.
} 
- Revista de Iniciação à Docência, v. 5, n. 3, 2020 -

Publicação: março, 2021 - ISSN 2525-4332

potencialidades, seus limites, seus traços e seus ritmos específicos. Ao mesmo tempo, ela propicia ao educador a revisão de seus procedimentos e até mesmo o questionamento de sua própria maneira de analisar a ciência e encarar o mundo. Ocorre, neste caso, um procedimento de mútua educação (p. 19).

A avaliação é vista como uma das atividades mais difíceis e polêmicas dentre as que são destinadas aos professores. A dimensão pedagógica é compreendida como a que implica diretamente com o processo de ensino e aprendizagem nas características de sua intencionalidade consciente e sistematização. Entende o autor que o trabalho do professor com os alunos passa por uma organização onde são incluídos os objetivos que se pretende alcançar, os conteúdos a trabalhar, a metodologia para poder desenvolver esse trabalho e também um processo de avaliação de resultados.

Nos Programas analisados há os tópicos: "a avaliação da aprendizagem em sala de aula: causas e finalidades da avaliação [... ]; concepção de avaliação [...]; erro - concepção e classificação. O erro como fonte de aprendizagem [...]; funções e propósitos da avaliação escolar [...]; regulação da aprendizagem. [...] Avaliação como prática de investigação; [...] avaliação educacional: das técnicas aos valores.

Pelo descrito nesses tópicos pode-se inferir que os programas de ensino consideram a dimensão pedagógica da avaliação e a relacionam com todos os elementos que são fundamentais para o trabalho do professor com o aluno, destacando a necessária coerência entre os elementos. A avaliação da aprendizagem adquire sentido a partir do momento em que é articulada com um projeto pedagógico. De acordo com Luckesi (2006), a avaliação auxilia nas decisões a serem tomadas a respeito da aprendizagem dos alunos, visando garantir qualidade do resultado que está sendo construído, e de tal maneira, não pode ser estudada, definida e delineada sem a adoção de um projeto que a articule.

O professor ao avaliar deve coletar, analisar e sintetizar de uma forma mais objetiva possível, as manifestações das condutas dos alunos, sendo elas cognitivas, afetivas e psicomotoras, produzindo uma configuração do que foi aprendido. Deverá também conceder uma qualidade a essa figura da aprendizagem, a partir de um nível de expectativa que é preestabelecido e aceito como válido a partir dos conteúdos que são trabalhados. Após tal qualificação deve tomar decisão de acordo com as novas condutas a serem seguidas, tendo em vista uma reorientação da aprendizagem se sua qualidade não for satisfatória ou avançar no trabalho com os conteúdos que estão sendo ensinados, considerando o que é essencial para a formação dos educandos.

Para construir os instrumentos de coleta de dados para a avaliação da aprendizagem devem ser consideradas algumas situações, entre elas: cobrir uma amostra significativa de todos os conteúdos ensinados; compatibilizar os níveis de dificuldade daquilo que está sendo avaliado com os níveis de dificuldade do que foi ensinado e aprendido; utilizar linguagem clara e compreensível para salientar o que se deseja pedir, sem confundir a compreensão dos educandos no instrumento de avaliação; construir instrumentos que auxiliem na aprendizagem dos alunos, pela demonstração da 
- Revista de Iniciação à Docência, v. 5, n. 3, 2020 -

Publicação: março, 2021 - ISSN 2525-4332

essencialidade dos conteúdos, por exercícios inteligentes ou aprofundamentos cognitivos propostos; e estar atento ao processo de correção e devolução dos instrumentos de avaliação da aprendizagem dos alunos (LUCKESI, 2006).

Considerando que o ato de avaliar se constitui em investigar se os objetivos estão realmente sendo alcançados visando orientar a aprendizagem e a construção do saber, os instrumentos por ela utilizados devem apresentar sentido orientador e cooperativo. Os programas de ensino estudados destacam entre os conteúdos: "[...] métodos, tipos, estratégias e procedimentos da avaliação escolar [...]; alguns instrumentos de avaliação da aprendizagem escolar. [...] Intervenção: procedimentos e estratégias. Quem avalia, o quê, quando, como, porque se avalia. [...] As notas e/ou outras formas de apreciação quantitativa ou qualitativa". Pode-se inferir, portanto, que os programas listados destacam os conteúdos relativos ao instrumental/procedimental proposto para a avaliação da aprendizagem.

Os demais conteúdos explicitados nos programas de ensino estudados e que dizem respeito à Didática são: “trajetória histórica da Didática" e "conhecimento e ação docente".

A Didática se refere ao ensino como processo para a construção do conhecimento. É definida como a ciência e a arte do ensino. A Didática é estudo necessário por ser uma disciplina essencial para exercer a profissão de professor. Nela são tratadas os atributos e funções apropriados ao ensino, desde a educação infantil até o ensino superior. É também conhecida por apresentar metodologias que favorecem o ensino nas mais diversas situações e contextos.

A Didática está presente no ensino dos cursos de graduação e pós-graduação e o foco nos processos de ensinar traz investigações, possibilidades de estruturação e de funcionamento das diferentes dimensões dos conhecimentos com objetivo de criar perspectivas de melhor ensinar. A Didática é disciplina de cursos de formação de professores que estuda o processo de ensino em seu conjunto, ou seja, os objetivos de ensino e os objetivos educativos, os métodos, os conteúdos científicos, as formas de organização do ensino, as condições e os meios que motivam os alunos para o estudo e para seu desenvolvimento global.

O objeto de estudo da Didática, o ensino, parte de duas ideias básicas. De um lado, a ideia de ensino e aprendizagem que relaciona e articula as dimensões humana técnica e político-social; de outro lado, temos a ideia que valoriza as diferentes formas de ensinar que integram o saber, o fazer e o ser, a racionalidade, a sensibilidade, a teoria e o tecnológico de que resultam os novos modos de pensar e de aprender (LIBÂNEO, 1991).

Haidt (1995) explicita que a Didática não pode tratar do ensino, parte do professor, sem pensar na aprendizagem, que é parte do aluno. Ela deveria enfatizar a relação professor-aluno na construção do conhecimento. O desafio é superar a dimensão técnica do ensinar. Outro desafio é propor alterações na forma de pensar e de agir do docente em uma construção que vem sendo ressignificada ao longo dos tempos a partir de diversos 
- Revista de Iniciação à Docência, v. 5, n. 3, 2020 -

Publicação: março, 2021 - ISSN 2525-4332

referenciais teóricos construídos e disponibilizados na literatura pedagógica.

De acordo com Libâneo (2002), os nexos entre o ato de ensinar e o ato de aprender, requerem atividades de mediação para promover o encontro formativo, educativo, entre o aluno e a matéria de ensino, explicitando o vínculo entre teoria do ensino e teoria do conhecimento. Por isso, é importante investigar os fundamentos, as condições e os modos de realizar a instrução e o ensino. Somente assim é possível transformar objetivos sóciopolíticos e pedagógicos em objetivos de ensino, selecionar conteúdos e métodos de acordo com esses objetivos e estabelecer vínculos entre ensino e aprendizagem (LIBÂNEO, 1991).

Santos (2014) afirma que quando Comenius instituiu o termo didática em sua obra, chamada Didática Magna, pretendeu pensar na "arte de ensinar tudo a todos", manifestando o desejo de democratização dos saberes e conhecimentos.

Porém, a trajetória histórica da Didática, especialmente no Brasil, indica que as necessidades educacionais e contexto social de cada época marcaram os escritos e as práticas dos professores e seus alunos de diferentes maneiras. No início, de forma instrumental e prescritiva, com base em teorias que pudessem manter a visão individualista de aprendizagem e a organização do saber sistematizado.

Até por volta dos anos de 1970 a Didática figurou com destaque na formação de professores e também no processo de ensino-aprendizagem sem questionamentos acerca da sua importância na concepção de uma nação. Mas, no começo dos anos de 1980, críticas e contestações foram explicitadas, versando sobre qual seria o verdadeiro significado da didática para construção de novas aprendizagens, inclusive a respeito da formação de cidadãos, colocando uma nova pauta de discussão e de estudos referentes a essa temática.

Santos (2014) explicita que o esvaziamento teórico-político da Didática na formação de professores e na superação da didática instrumental foi necessário e propulsor de um novo tempo na educação. Nas palavras de Candau (2002 apud Santos, 2014, p. 3):

\begin{abstract}
A didática passa por um momento de revisão crítica. Tem-se a consciência da necessidade de superar uma visão meramente instrumental e pretensamente neutra do seu cotidiano. Trata-se de um momento de perplexidade, de denúncia e anúncio, de busca de caminhos que tem de ser construídos através do trabalho conjunto dos profissionais da área com professores de $1^{\circ} \mathrm{e} 2^{\circ}$ graus. E pensando a prática pedagógica concreta, articulada com a perspectiva de transformação social, que emergirá uma nova configuração para a Didática.
\end{abstract}

A Didática rompeu com sua função prescritiva e instrumental e depois manifestouse com a variação entre as didáticas e metodologias e ensino. O entendimento do processo formativo, indispensável para atuação docente, tanto na formação inicial como no decorrer da profissão, foi marcado por constantes aperfeiçoamentos de práticas, conhecimentos e saberes. O trabalho docente inclui elementos resultantes da sua experiência e também do seu processo formativo, o que possibilita a cada professor e situação um trabalho único. 
- Revista de Iniciação à Docência, v. 5, n. 3, 2020 -

Publicação: março, 2021 - ISSN 2525-4332

Santos (2014, p. 8) citando Lee S. Shulman ressalta que alguns conhecimentos devem ser essenciais para a prática profissional:

\begin{abstract}
Conhecimento do conteúdo: conhecimentos gerais, em material didático, especialmente tendo em vista os princípios e estratégias de gestão e organização a classe para além do âmbito do sujeito. Conhecimento do currículo, com um domínio especial de materiais e programas que servem como ferramentas para o trabalho de professores. Conhecimento do conteúdo pedagógico, que o amalgama especial matéria e pedagógica que é uma área exclusiva de professores, sua própria forma especial de entendimento profissional; conhecimento dos alunos e suas características; conhecimento dos contextos educativos, que vão desde o funcionamento do grupo ou classe, gestão e financiamento distritos escolares para o caráter de comunidade e culturais, e; conhecimento dos objetivos, propósitos e valores educacionais e da sua filosofia e histórica (SHULMAN, 2005).
\end{abstract}

Portanto, quando os programas de ensino tratam da: "trajetória histórica da didática" e "conhecimento e ação docente" demonstram preocupação com os aspectos do processo formativo que permitem refletir acerca do trabalho docente como construção a ser realizada em bases pedagógicas sólidas.

Freire e Skeika (2015) apontam que um bom professor é aquele que consegue transitar entre os diferentes conhecimentos para o ensino fazendo uso de cada um deles no momento que julga adequado, de maneira que a prática de ensino de um determinado conteúdo conduza os alunos à aprendizagem. Para os autores, reforçar o que Tardif (2002, apud Freire e Skeika, 2015) indica a respeito do saber do professor organizado a partir de seis elementos condutores é muito importante:

1) Saber e trabalho - é preciso compreender o saber do professor em íntima relação com o trabalho na escola e na sala de aula; 2) Diversidade do saber - o saber dos professores é plural, compósito e heterogêneo, envolve um saber-fazer variado e de diferentes naturezas; 3) Temporalidade do saber - o saber dos professores é temporal, adquirido no contexto de uma história de vida e de uma carreira profissional; 4) A experiência de trabalho enquanto fundamento do saber - focaliza os saberes oriundos da experiência do trabalho cotidiano como alicerce da prática e das competências profissionais; 5) Saberes humanos a respeito de saberes humanos - representa o saber originado no fazer docente por meio da interação humana do professor com o seu objeto de trabalho; 6) Saberes e formação profissional - é decorrente dos outros saberes e expressa a necessidade de repensar a formação para o magistério em função dos saberes dos professores e o cotidiano de seu trabalho (FREIRE; SKEIKA, 2015, p. 17067).

Os programas de ensino estudados quando expressam que se preocupam com a trajetória de construção do trabalho didático do professor dão pistas para contemplar os elementos norteadores propostos anteriormente. A responsabilidade e o compromisso dos profissionais em pesquisar e transmitir conhecimentos necessários para a melhoria da educação só é possível se houver na mesma proporção a formação equivalente. Os elementos descritos na citação de Freire e Skeika (2015) são claros ao definirem que o ensino só será bem sucedido se for analisado para além do conteúdo próprio de uma área 
- Revista de Iniciação à Docência, v. 5, n. 3, 2020 -

Publicação: março, 2021 - ISSN 2525-4332

do conhecimento. Ensinar Matemática é muito importante. Na mesma proporção, estudar para bem ensinar Matemática também é essencial.

Convém destacar ainda que a possibilidade de olhar para a didática ensinada nas referidas disciplinas, mesmo que de maneira acanhada e parcial, registra alguns aspectos pedagógicos que são mobilizadores da construção e constituição do conhecimento da área. Na próxima seção, apresentaremos a possível conclusão do estudo por meio das considerações finais.

\section{Considerações finais}

O presente estudo analisou a contribuição dos conteúdos da Didática, presentes nos programas das disciplinas de Didática e Epistemologia das Ciências e A Avaliação da Aprendizagem Escolar relativas ao Programa de Pós-Graduação em Ensino de Ciências e Educação Matemática da UEL e verificou quais são as bases teórico-metodológicas da formação de professores que foram veiculadas nos referidos programas de ensino entre os anos de 2012 e 2017.

Por meio da utilização dos pressupostos da metodologia qualitativa, as formas de pesquisa bibliográfica e documental auxiliaram a responder a questão norteadora: Como os programas das disciplinas de didática no contexto de curso stricto sensu, favorecem a formação do professor da área da Matemática? Para tanto foi preciso aprofundar a leitura da literatura pedagógica para conceituar e contextualizar a Didática, seu objeto de estudo e sua trajetória na formação de professores.

Os resultados indicam que os programas de ensino das disciplinas investigadas consideram a dimensão pedagógica da formação de professores de Matemática ao tratarem de elementos que são essenciais para o trabalho relativo à Didática e à Avaliação da Aprendizagem. Sendo assim, encontram suas bases teóricas no debate contemporâneo sobre o ensino de Didática, com vistas a assimilação dos princípios e das práticas que concebem os trajetos da gênese pedagógica e sociopolítica do professorado.

Podemos concluir que quando tratam de estudar o processo de ensino em seu conjunto, as formas de organização, as condições e os meios para evidenciar aprendizagem, estão colaborando para que a formação dos alunos de stricto sensu avance em direção à pesquisa referente ao ensino da Matemática e, especialmente, denotam a preocupação com o ensino da Matemática para além de conteúdos específicos.

Os conhecimentos adquiridos durante este estudo trouxeram a percepção de que para uma boa atuação docente é preciso sempre buscar mais conhecimentos relativos ao que se pretende ensinar e ao como ensinar. $O$ trabalho dos professores envolve saberes plurais e de diferentes naturezas e, portanto, envolve seres humanos em diferentes épocas e contextos. Neste momento, a construção do conhecimento por meio deste trabalho de iniciação científica é sem dúvida, o início de outros tantos plurais e contextuais necessários. 
- Revista de Iniciação à Docência, v. 5, n. 3, 2020 -

Publicação: março, 2021 - ISSN 2525-4332

\section{Referências}

BERBEL, N. A. N. Dimensão pedagógica. In: BERBEL, N. A. N. et al. Avaliação da aprendizagem no ensino superior: um retrato em cinco dimensões. Londrina/PR: EDUEL, 2001, p. 21-88.

COURA, F. C. F.; PASSOS, C. L. B. Estado do conhecimento sobre o formador de professores de Matemática no Brasil. Zetetiké. Campinas/SP, v. 25, n. 1, 2017, p. 7-26.

FREIRE, L. I. F.; SKEIKA, T. Conhecimentos e saberes necessários para a docência: contribuições do processo formativo e da experiência profissional. XIV Congresso Nacional de Educação - EDUCERE, V Seminário Internacional de Representações Sociais, Subjetividade e Educação VII Seminário Internacional sobre Profissionalização Docente. Curitiba, 2015. Anais... Editora Universitária Champagnat, Curitiba, 2015, p. 17064-17074.

HAIDT, R. C. C. Curso de didática geral. São Paulo/SP: Ática, 1995.

LIBÂNEO, J. C. Didática. São Paulo/SP: Cortez, 1991.

LIBÂNEO, J. C. Didática: velhos e novos temas. Goiânia/GO: Edição do autor, 2002.

LUCKESI, C. C. Avaliação da aprendizagem escolar. São Paulo/SP: Cortez, 2006.

LUDKE, M.; ANDRÉ, M. E. D. A. Pesquisa em educação: abordagens qualitativas. São Paulo/SP: EPU, 1986.

MANIFESTO contra a supressão da Didática dos currículos dos cursos de formação de professores: luta pelo reempoderamento docente por meio da reapropriação da didática na itinerância formativa dos licenciados. Disponível em:<http://eventos.uece.br> Acesso em: 27 ago. 2018.

MINAYO, M. C. S. Ciência, técnica e arte: o desafio da pesquisa social. In: MINAYO, M. C. S. (Org.). Pesquisa social: teoria, método e criatividade. Petrópolis/RJ: Vozes, 1994, p. 9-29.

SANTOS, H. C. A Didática no Brasil: sua trajetória e finalidade. Estação Científica. Juiz de Fora/MG, n. 11, 2014, p. 1-15.

SHULMAN, L. S. Conhecimento e ensino: fundamentos da nova reforma. Jornal da formação de professores e currículo, v. 9, n. 2, 2005.

UNIVERSIDADE ESTADUAL DE LONDRINA. UEL em dados. Londrina/PR: UEL, 2019.

Disponível em: < http://www.uel.br/proplan/novo/pages/arquivos/uel_em_dados/UEL-em-dados_2019.pdf>. Acesso em 23 abr.2019.

UNIVERSIDADE ESTADUAL DE LONDRINA. Programa de Pós-Graduação em Ensino de Ciências e Educação Matemática. Londrina/PR: UEL, 2019. 